\title{
Risky Business: Multinationals, Uncertainty and Asymmetric Insurance
}

\author{
By GERDA DEwIT \\ National University of Ireland, Maynooth
}

Final version received 21 May 2001.

\begin{abstract}
A partial equilibrium model is used to examine the international production allocation of a two-plant multinational firm that is confronted with uncertainty with respect to foreign sales. The firm produces identical products in both plants, using firm-specific factors. The internationally price-discriminating multinational has monopoly power in both segmented markets. The analysis focuses on how asymmetric insurance facilities between the firm's home and host country influence its international production allocation and level of intra-firm trade.
\end{abstract}

\section{INTRODUCTION}

Risk management is vital to multinational enterprises (MNEs) facing uncertainty in foreign markets. One strand of the MNE literature demonstrates this by showing how various risks for which insurance does not exist ${ }^{1}$ alters MNEs' international production decisions compared with when they operate under certainty. Other work deals with sources of uncertainty against which firms can hedge in financial markets. ${ }^{2}$ In this paper MNE behaviour is examined in the presence of risks for which insurance markets are missing but public insurance schemes are available instead. Such insurance schemes differ in one important respect from the coverage mechanisms available in financial markets. In forward and futures markets, firms can typically hedge without restrictions. By contrast, owing to the government's involvement, public insurance alternatives tend to lack the global character of financial markets and often include explicit support for domestic economic activities.

This paper contributes to the literature on MNE behaviour under uncertainty by examining how biased public insurance schemes affect the MNE's international allocation of production and sales. The issue is studied here by concentrating on foreign commercial risk. The analysis is particularly relevant for MNEs that are active in emerging markets or economies in transition, where the potential for investment is vast but commercial risks are high. Several stylized facts motivate the decision to concentrate on this form of foreign revenue uncertainty. First, the increased use of export credits has raised the exposure of international firms to the risk of commercial default. ${ }^{3}$ Second, the bulk of export credits is concentrated in former planned economies and newly developing markets. ${ }^{4}$ Because commercial default often occurs in clusters, this regional concentration has the potential to cause huge revenue losses. It has been argued that commercial risks in 'new' markets have been sufficient to discourage investment. ${ }^{5}$ This suggests that MNEs exhibit a considerable degree of risk aversion towards investing in these regions and that financial tools used by 
MNEs are far from adequate to manage these commercial risks properly. Third, the markets targeted are still poorly developed and typically lack an efficient financial system. Local credit markets suffer from severe asymmetric information problems, ${ }^{6}$ and because of these problems insurance markets remain largely undeveloped.

The lack of facilities to manage commercial risk in the foreign country contrasts with the public provision of export credit insurance in the MNE's home country. This asymmetry in insurance facilities is caused by the fact that the official export insurance schemes in the home country are inseparably linked to export activities, thus excluding coverage of foreign sales produced in the host plant. It will be shown that, compared with hedging facilities in global financial markets, these public risk management instruments affect the international production allocation of MNEs differently.

In Section I a partial equilibrium $\operatorname{model}^{7}$ is specified, in which an internationally price-discriminating MNE faces revenue uncertainty in its host market. In Section II the MNE's international production and sales allocation is derived under foreign payment uncertainty. Section III first examines the effects of public export insurance on inter-subsidiary trade and on the MNE's distribution of production and sales; then the MNE's optimal production response to a change in the export insurance premium rate is discussed. The final section highlights the wider relevance of the analysis and formulates some concluding remarks.

\section{The Multinational Firm And COMmercial RisK IN THE HOST MARKET}

Consider an internationally price-discriminating MNE with a home and a foreign plant, exercising monopoly power in both the home and the host market. Both plants produce ${ }^{8}$ an identical good. ${ }^{9}$ Outputs in the home and the host plant are represented by $x$ and $x^{*}$ respectively, whereas $q$ and $q^{*}$ denote sales in the respective markets. The respective production costs in the home and the host plant are represented by $C(x)$ and $C^{*}\left(x^{*}\right)$, with $C^{\prime}(x)>0$, $C^{* \prime}\left(x^{*}\right)>0, C^{\prime \prime}(x)>0$ and $C^{* \prime \prime}\left(x^{*}\right)>0$. Increasing marginal costs reflect that production requires the use of at least one firm-specific factor. ${ }^{10}$ Home and foreign revenue functions are given by $R(q)$ and $R^{*}\left(q^{*}\right)$, with $R^{\prime}(q)>0$, $R^{* \prime}\left(q^{*}\right)>0, R^{\prime \prime}(q)<0$ and $R^{* \prime \prime}\left(q^{*}\right)<0$.

The firm's contracts with foreign buyers stipulate a credit term, thus allowing deferral of payment for the period specified. This mode of payment implies that the firm is confronted with a risk of default in the foreign market. The probability that default occurs is exogenously given by a constant, $\alpha .{ }^{11}$ The fraction of the contract value defaulted by the foreign buyer is denoted by $\lambda$, a stochastic variable with support ]0,1] and probability density $f_{\lambda}$.

Without insurance, the MNE's expected profits $(E \pi)$ are

$$
E \pi=(1-\alpha) \pi_{0}+\alpha \int_{\lambda} \pi_{\lambda} f_{\lambda} \mathrm{d} \lambda
$$

(C) The London School of Economics and Political Science 2002 
where $E$ denotes the expectation operator and with

$$
\begin{aligned}
& \pi_{0}=R(q)+R^{*}\left(q^{*}\right)-C(x)-C^{*}\left(x^{*}\right), \\
& \pi_{\lambda}=R(q)+(1-\lambda) R^{*}\left(q^{*}\right)-C(x)-C^{*}\left(x^{*}\right), \\
& x+x^{*}=q+q^{*},
\end{aligned}
$$

where $\pi_{0}$ stands for the firm's profits if full payment is received when the credit term expires, while $\pi_{\lambda}$ represents profits when the foreign buyer defaults. The discount factor is set equal to 1 . The MNE's total output has to be equal to its total sales, which is reflected in expression (3).

\section{The MnE's International Allocation Without Insurance}

This section highlights how the risk of foreign default affects the MNE's allocation of production and sales between the home and the host country when insurance is not available.

Financial markets do not insulate firms from commercial risk (see Stephens 1999). Hence, when facing this type of uncertainty MNEs typically do not make output and sales decisions as if they are risk-neutral.

Assumption 1. The MNE is risk-averse.

So, given a von Neumann-Morgenstern utility function, $U(\pi)$ with $U^{\prime}(\pi)>0$, we have $U^{\prime \prime}(\pi)<0$. The MNE maximizes expected utility, $E U$, or

$$
\max _{x_{r}, x_{r}^{*}, q_{r}^{*}} E U=(1-\alpha) U\left(\pi_{0}\right)+\alpha E U\left(\pi_{\lambda}\right)
$$

with $q_{r}=x_{r}+x_{r}^{*}-q_{r}^{*}$ and $E U\left(\pi_{\lambda}\right)=\int_{\lambda} U\left(\pi_{\lambda}\right) f_{\lambda} \mathrm{d} \lambda$.

Subscript $r$ refers to the fact that the variables are chosen under uncertainty and without insurance. The respective first-order conditions for $x_{r}, x_{r}^{*}$ and $q_{r}^{*}$ derived from (4) are given by ${ }^{12}$

$$
\begin{aligned}
& R^{\prime}\left(q_{r}\right)=C^{\prime}\left(x_{r}\right), \\
& R^{\prime}\left(q_{r}\right)=C^{*^{\prime}}\left(x_{r}^{*}\right), \\
& R^{\prime}\left(q_{r}\right)=\left(1-\alpha \frac{E U^{\prime}\left(\pi_{\lambda}\right) E \lambda+\operatorname{cov}\left(U^{\prime}\left(\pi_{\lambda}\right), \lambda\right)}{E U^{\prime}(\pi)}\right) R^{* \prime}\left(q_{r}^{*}\right),
\end{aligned}
$$

with $E U^{\prime}\left(\pi_{\lambda}\right)=\int_{\lambda} U^{\prime}\left(\pi_{\lambda}\right) f_{\lambda} \mathrm{d} \lambda$ and $E U^{\prime}(\pi)=(1-\alpha) U^{\prime}\left(\pi_{0}\right)+\alpha E U^{\prime}\left(\pi_{\lambda}\right)$. The value for $q_{r}$ then follows immediately from the sales-output equality given in (4).

To assess the effect of payment uncertainty on the international production and sales allocation, the uncertainty regime is contrasted with its certainty counterpart. When the payment loss is $\alpha E \lambda$ with certainty, the optimization problem is

$$
\max _{x_{c}, x_{c}^{*}, q_{c}^{*}} U(\pi(\alpha E \lambda))
$$

with $\pi(\alpha E \lambda)=R\left(q_{c}\right)+(1-\alpha E \lambda) R^{*}\left(q_{c}^{*}\right)-C\left(x_{c}\right)-C^{*}\left(x_{c}^{*}\right)$. The respective first-order conditions for $x_{c}, x_{c}^{*}$ and $q_{c}^{*}$ (where subscript $c$ refers to the levels 
of the variables under certainty) are

$$
\begin{aligned}
& R^{\prime}\left(q_{c}\right)=C^{\prime}\left(x_{c}\right), \\
& R^{\prime}\left(q_{c}\right)=C^{* \prime}\left(x_{c}^{*}\right), \\
& R^{\prime}\left(q_{c}\right)=(1-\alpha E \lambda) R^{*^{\prime}}\left(q_{c}^{*}\right),
\end{aligned}
$$

with $q_{c}=x_{c}+x_{c}^{*}-q_{c}^{*}$. Proposition 1 states the effects of the risk of foreign default on output and sales.

Proposition 1. With the risk of foreign default and without insurance facilities, the MNE (i) sells more in the home market $\left(q_{r}>q_{c}\right)$, (ii) sells less in the host market $\left(q_{r}^{*}<q_{c}^{*}\right)$ and (iii) produces less in both the home and the host plant $\left(x_{r}<x_{c}\right.$ and $\left.x_{r}^{*}<x_{c}^{*}\right)$ than under certainty. ${ }^{13}$

In the next section the effects of export insurance schemes on intersubsidiary trade, production and sales are discussed. The discussion highlights the differences between these schemes and the financial hedging mechanisms available for other types of revenue uncertainty.

\section{MNE BEHAVIOUR WITH EXPORT CREDIT INSURANCE}

Assume that the MNE's home plant is a net exporter to its plant in the host country. Insurance against the risk of foreign default is, unlike financial hedging mechanisms, typically not provided by the market. Therefore, governments in developed countries tend to offer public insurance schemes instead; such schemes are, however, unavailable in most developing countries.

Assumption 2. Insurance against the risk of default is absent in the MNE's host country, but is available in the home country for home exports.

Assumption 2 is based on the stylized fact that publicly provided insurance against the risk of foreign default is typically restricted to exports from the home country and does not cover the risk on the products that are produced and sold in the host country. ${ }^{14}$ This implies that a coverage constraint prevails for the MNE, given by

$$
I \leqslant R^{*}\left(q^{*}\right)-p^{*}\left(q^{*}\right) x^{*},
$$

where $I$ is the sum covered by insurance, $p^{*}$ stands for the price in the foreign market, and the right-hand side of the constraint is equal to the value of the MNE's exports to the foreign market. ${ }^{15}$ Profits now include the costs and benefits of export insurance and are given by

$$
\begin{aligned}
& \pi_{0}=R(q)+R^{*}\left(q^{*}\right)-C(x)-C^{*}\left(x^{*}\right)-\rho I, \\
& \pi_{\lambda}=R(q)+(1-\lambda) R^{*}\left(q^{*}\right)-C(x)-C^{*}\left(x^{*}\right)+(\lambda-\rho) I,
\end{aligned}
$$

where $\rho$ represents the export insurance premium per currency unit insured.$^{16}$ If the foreign importer defaults and $\pi_{\lambda}$ is realized, the fraction of the export 
contract that remained unpaid will be reimbursed by the official insurance company to the extent that coverage is taken (i.e. $\lambda I$ ).

The MNE now maximizes the Lagrangian $(L)$, i.e.

$$
\max _{x_{I}, x \tilde{T}, q \tilde{T}, I, \varphi} L=E U+\varphi\left(R^{*}\left(q_{I}^{*}\right)-p^{*}\left(q_{I}^{*}\right) x_{I}^{*}-I\right),
$$

with $q_{I}=x_{I}+x_{I}^{*}-q_{I}^{*}$, where subscript $I$ denotes the values of the decision variables with export insurance. The Lagrange multiplier associated with the coverage constraint is denoted by $\varphi$. The respective first-order conditions for $x_{I}, x_{I}^{*}$ and $q_{I}^{*}$ are given by ${ }^{17}$

$$
R^{\prime}\left(q_{I}\right)=C^{\prime}\left(x_{I}\right)
$$

$$
\begin{aligned}
R^{\prime}\left(q_{I}\right)= & C^{* \prime}\left(x_{I}^{*}\right)+\frac{\varphi}{E U^{\prime}(\pi)} p^{*}\left(q_{I}^{*}\right), \\
R^{\prime}\left(q_{I}\right)= & \left(1-\frac{\alpha\left[E U^{\prime}\left(\pi_{\lambda}\right) E \lambda+\operatorname{cov}\left(U^{\prime}\left(\pi_{\lambda}\right), \lambda\right)\right]-\varphi}{E U^{\prime}(\pi)}\right) R^{*^{\prime}}\left(q_{I}^{*}\right) \\
& -\frac{\varphi}{E U^{\prime}(\pi)} p^{*^{\prime}}\left(q_{I}^{*}\right) x_{I}^{*},
\end{aligned}
$$

with $p^{* \prime}\left(q_{I}^{*}\right)<0$. Furthermore, if the constraint is not binding $(\varphi=0)$, the firm does not insure its exports completely $\left(I<R^{*}\left(q_{I}^{*}\right)-p^{*}\left(q_{I}^{*}\right) x_{I}^{*}\right)$, and the firstorder condition for $I$ is equal to

$$
\rho=\alpha \frac{E U^{\prime}\left(\pi_{\lambda}\right) E \lambda+\operatorname{cov}\left(U^{\prime}\left(\pi_{\lambda}\right), \lambda\right)}{E U^{\prime}(\pi)} .
$$

However, if the constraint is binding $\left(I=R^{*}\left(q_{I}^{*}\right)-p^{*}\left(q_{I}^{*}\right) x_{I}^{*}\right)$, the first-order condition for $I$ is given by

$$
\varphi=\alpha\left(E U^{\prime}\left(\pi_{\lambda}\right) E \lambda+\operatorname{cov}\left(U^{\prime}\left(\pi_{\lambda}\right), \lambda\right)\right)-\rho E U^{\prime}(\pi)>0 .
$$

Expressions (10a)-(10e) are crucial for the discussion in the following subsections, which concentrates on three questions: (a) How does public export insurance affect inter-subsidiary trade? (b) How does public export insurance affect the MNE's international distribution of production and sales? (c) How does the MNE's production distribution respond to a change in the cost of export insurance?

\section{(a) Export insurance and intra-MNE trade}

Here, intra-firm trade is calculated for the case with export insurance and compared with trade without export insurance. First, suppose that export insurance is unavailable and that the prevailing revenue and cost functions in the home and the host country imply that the firm's inter-subsidiary trade volume is equal to $v\left(x_{r}-q_{r}=v\right)$. Next, consider the case in which export insurance is available in the home country. Compared to the case without export insurance, export revenues are worth more to the firm since their 
variability can be reduced through insurance coverage. Hence, everything else being equal, a higher level of trade will now take place from the MNE's home to its host plant (or, $x_{I}-q_{I}>v$ ).

Proposition 2. With export insurance, intra-MNE trade is higher than without export insurance $\left(x_{I}-q_{I}>x_{r}-q_{r}\right)$.

Proof. See Appendix.

\section{(b) Export insurance and the separation property}

Using the first-order conditions (10a)-(10e), this section examines how export insurance affects the MNE's international allocation of outputs and sales. As a preliminary, it is instructive to describe MNE behaviour in financial markets, which will serve as a benchmark for comparison. ${ }^{18}$

Consider a MNE that faces exchange rate uncertainty about its future revenues expressed in a foreign currency. Through hedging against this risk by selling its future currency revenues at the rate prevailing in the forward market, the MNE can reduce or even eliminate its exposure to future exchange rate fluctuations. Unlimited hedging enables the firm to insulate itself optimally from exchange rate fluctuations. As a result, its outputs and sales are influenced only by the forward rate. Alternatively, in the terminology used in the insurance literature, a separation property prevails, referring to the fact that output and sales remain unaffected by the firm's attitude to risk and the features of the distribution function of the exchange rate. ${ }^{19}$

In contrast to financial hedging mechanisms, public export insurance typically entails a coverage restriction. Because of that restriction a separation property may not hold. A clear distinction needs to be made between the cases when the export insurance coverage constraint is binding and when it is not.

First, consider the case in which the prevailing premium rate is sufficiently high for the coverage constraint not to be binding (see (10d)). This implies that the MNE chooses to cover less than its total export revenues $\left(I<R^{*}\left(q_{I}^{*}\right)-p^{*}\left(q_{I}^{*}\right) x_{I}^{*}\right)$. Without hitting the coverage constraint, the MNE effectively purchases the level of coverage it wishes to buy, not just for its export revenues, but for its total risky foreign revenues. Hence, at the prevailing premium rate, the firm attains its optimal level of insulation from foreign revenue fluctuations. It then chooses its output and sales independently of its attitude towards risk and the distribution of the default rate. ${ }^{20}$ Only the cost of insurance (i.e. the premium rate) determines the MNE's production allocation between markets. Thus, a separation property applies in this case and public export insurance operates like hedging mechanisms in financial markets.

However, if at the prevailing premium rate the MNE wishes a level of coverage that exceeds its export revenues eligible for insurance, then the constraint is binding (see (10e), with $\varphi>0$ and $\left.I=R^{*}\left(q_{I}^{*}\right)-p^{*}\left(q_{I}^{*}\right) x_{I}^{*}\right)$. The MNE's coverage level is now 'suboptimal' in the sense that the firm is left with risk that it wants to but cannot insure. This is reflected in its international output and sales allocation, which now depends crucially on the firm's attitude to risk and the distribution of the foreign default rate. In other words, there is 
no separation property at premium rates that are 'sufficiently low' for the coverage constraint to be binding.

Definition. Let $\bar{\rho}$, henceforth referred to as the critical premium rate, be the minimum export insurance premium rate for which the coverage constraint is not binding in the MNE's insurance decision.

From the definition, the coverage constraint is not binding at premium rates above or equal to the critical rate $(\rho \geqslant \bar{\rho})$, but is binding at premium rates below the critical rate $(\rho<\bar{\rho})$.

Proposition 3. With export insurance, the MNE's outputs $\left(x_{I}, x_{I}^{*}\right)$ and sales $\left(q_{I}, q_{I}^{*}\right)$

(i) are unaffected by its risk aversion and by the distribution features of the default rate when the prevailing premium rate is higher than or equal to the critical premium rate $(\rho \geqslant \bar{\rho})$;

(ii) are influenced by its risk aversion and by the distribution features of the default rate when the prevailing premium rate is strictly lower than the critical premium rate $(\rho<\bar{\rho})$.

\section{Proof. See Appendix.}

Note that premium rates in the range $\rho \geqslant \bar{\rho}$ are all higher than the 'fair' rate, which is defined as the rate at which the insurer breaks even $\left(\rho^{f} \equiv \alpha E \lambda\right){ }^{21}$ Hence, at the fair premium rate $\left(\rho^{f}<\bar{\rho}\right)$ the MNE's output and sales will be affected by the uncertainty through the firm's attitude towards risk (see Proposition 3(ii)). So, although the fair premium is equal to the loss in the certainty case $(\alpha E \lambda)$, outputs and sales will differ from their levels under certainty. Although the firm wants full coverage of its total foreign risky revenues $\left(R^{*}\left(q_{I}^{*}\right)\right)$ at $\rho^{f}$, it cannot obtain it. Therefore, since only export revenues are covered by export insurance, the MNE is induced to keep its production in the foreign plant below the certainty output and to serve the foreign market by exporting more from the home plant than under certainty. Higher exports allow the firm to cover more of the foreign sales by the public export insurance scheme. Such a home-plant bias is absent when MNEs hedge against exchange rate uncertainty in the forward market, simply because their outputs and sales remain independent of their attitude to risk. Thus, Proposition 3 leads to the following corollary.

Corollary. With fair export insurance $\left(\rho=\rho^{f} \equiv \alpha E \lambda\right)$, the MNE

(i) produces more and sells less in its home country $\left(x_{I}>x_{c} ; q_{I}<q_{c}\right)$,

(ii) produces less in its host country $\left(x_{I}^{*}<x_{c}^{*}\right)$, and

(iii) trades more between its subsidiaries

than under certainty.

Proof. See Appendix.

(C) The London School of Economics and Political Science 2002 


\section{(c) Premium rate changes and the MNE's international production allocation}

This section focuses on how changes in the premium rate alter the MNE's production allocation between the home and the host plant. This issue is important given that, in 1999, the World Trade Organization (WTO) strengthened its rules regarding the use of export insurance subsidization (see Finger and Schuknecht 1999) and the OECD Arrangement stipulated minimum premium rates for the first time. During the 1980s and 1990s export insurance was subsidized substantially, in spite of the WTO prohibition (see Abraham et al. 1992; Kuhn et al. 1995; and Stephens 1999). If forced to comply with WTO rules, governments will have to gradually raise export insurance premium rates to the minimum rates determined by the OECD. While MNEs evidently benefit from export insurance subsidies, it is less clear how they respond to a change in the export insurance premium rate. It will be shown (see Proposition 4) that the MNE may alter output in the home and in the host plant in opposite directions. ${ }^{22}$

When export insurance is subsidized ( $\rho<\alpha E \lambda)$, it follows directly from (10e) that the coverage constraint is binding $\left(\varphi>0\right.$ and $\left.I=R^{*}\left(q_{I}^{*}\right)-p^{*}\left(q_{I}^{*}\right) x_{I}^{*}\right)$. Thus, in addition to its direct effect on outputs, the premium change also influences outputs indirectly via the firm's attitude to risk. More specifically, a reduction in the export insurance premium rate in general has three distinct effects, which will be referred to as the export subsidy effect, the risk aversion effect and the prudence effect.

First, the lower premium rate effectively means that firms now receive a higher export subsidy. This decreases the cost of exporting from the home country, while making producing in the host plant less attractive. Hence this export subsidy effect operates towards an expansion of the MNE's production in its home plant and a contraction of production abroad. ${ }^{23}$

Second, the premium reduction makes insurance cheaper, which induces firms to buy more insurance, allowing them to reduce their risk exposure and hence the undesirable fluctuations in utility $\left(U^{\prime \prime}<0\right.$, thus $\left.\operatorname{cov}\left(U^{\prime}\left(\pi_{\lambda}\right), \lambda\right)>0\right)$. Being constrained in its coverage decision, the only way a MNE can increase coverage of its foreign sales is by replacing part of its foreign production by more exports from the home plant. Thus, this effect, caused by risk aversion, reinforces the first (export subsidy) effect.

However, there is a third effect generated by a premium decrease, which tends to lower a firm's demand for insurance and hence opposes the other two effects. Suppose that firms exhibit constant absolute risk aversion (CARA). In addition to disliking fluctuations in utility, firms exhibiting CARA also dislike fluctuations in marginal utility. This means that their marginal utility is convex in profits $\left(U^{\prime \prime \prime}>0\right.$; thus $\left.\operatorname{cov}\left(U^{\prime \prime}\left(\pi_{\lambda}\right), \lambda\right)<0\right),{ }^{24}$ and implies that firms exhibit 'prudence'. ${ }^{25}$ A profit increase induced by a premium reduction dampens the fluctuations in marginal utility, thus lessening the MNE's need for insurance and reducing its incentive to cut back production in the foreign country.

Whether a MNE will actually contract production in the host plant when the export insurance premium is lowered depends on these three effects combined. Proposition 4 states a sufficient condition for a reduction in production abroad. 
Proposition 4. With subsidised export insurance $(\rho<\alpha E \lambda)$ and under CARA, $-\left(U^{\prime \prime} / U^{\prime}\right) \geqslant 1$ is a sufficient condition for $\mathrm{d} x_{I} / \mathrm{d} \rho<0$ and $\mathrm{d} x_{I}^{*} / \mathrm{d} \rho>0$.

Proof. See Appendix.

Thus, if sufficiently risk-averse, the reduction in marginal utility variability (i.e. the prudence effect) induced by the premium reduction is dominated by the firm's desire to limit its exposure to risk (i.e. the risk aversion effect). ${ }^{26}$ The above analysis suggests that, if governments are forced to raise their export insurance premium rates because of the strict imposition of WTO rules, MNEs may be induced to increase their production activities abroad, while loosening their anchorage at home. ${ }^{27}$

\section{CONCLUSION}

The analysis has shown that, compared with the unrestricted risk management facilities provided by global financial markets, insurance facilities managed by the government may affect MNEs differently owing to the built-in coverage conditions. This has been illustrated for the case where MNEs face foreign commercial risk, for which there is no insurance market but for which the home government typically offers export insurance schemes, often at a subsidized premium rate. Compared with the case where MNEs hedge against exchange rate uncertainty in the forward market, MNEs that face foreign payment uncertainty and can rely on official export insurance skew production towards the home plant and away from the host country. Hence the home government's official insurance schemes tend to favour domestic factors of production, while those in the host country may be harmed. In addition, the built-in exclusivity of public export insurance schemes also affects how MNEs adjust the production allocation between their plants, when confronted with a change in the premium rate. This question is particularly important in the context of the WTO's renewed commitment to curtail export insurance subsidies.

Throughout the analysis, the probability of default was assumed to be exogenous. However, it may be possible for firms to affect the occurrence of default to some extent by so-called 'self-protection' activities. These entail, for example, checking the foreign buyer's creditworthiness by gathering information about his guarantees. Since obtaining this information is costly, firms will not engage in such activities if full insurance is available and if the insurer cannot monitor efforts in self-protection. It is a well established result in the insurance literature ${ }^{28}$ that this moral hazard problem is partly alleviated if the risk-averse firm is left with some risk, which induces optimal care-taking behaviour by the (partially) insured. Asymmetries in the availability of insurance schemes, leaving the MNE with some non-insurable risk, may therefore mitigate potential moral hazard problems.

Finally, MNEs usually face a multitude of risks. Although exchange rate risk may be the most obvious one, it is unlikely that foreign direct investment (FDI) in emerging markets would be hampered significantly by this particular source of uncertainty, since financial markets provide unrestricted hedging facilities. However, MNEs operating in emerging and transition economies 
often face policies by local governments that would reinforce the conclusions of the analysis here provided, especially if other sources of non-insurable risk are considered. Cost uncertainty, for instance, combined with local content rules illustrates this. By forcing the MNE's foreign plant to purchase a certain fraction of its inputs in the host country, the MNE not only forgoes potentially cheaper imported inputs but also is subject to the price variability of local inputs. The combination of risk-mitigating government services at home and risk-exacerbating policies abroad may therefore severely curtail FDI in emerging economies, in spite of the huge investment potential in those markets.

\section{APPENDIX}

\section{Proof of Proposition 2}

The proof follows immediately from a comparison between (5a)-(5c) and (10a)-(10c). Suppose $x_{I} \leqslant x_{r}$. Then, $q_{I} \geqslant q_{r}$ from (5a) and (10a). Since $\varphi \geqslant 0$, this also implies $C^{*}\left(x_{I}^{*}\right) \leqslant C^{* \prime}\left(x_{r}^{*}\right)$ from $(5 \mathrm{~b})$ and $(10 \mathrm{~b})$ and hence $x_{I}^{*} \leqslant x_{r}^{*}$. Moreover, non-prohibitive premium rates imply that $\rho$ is smaller than the second term within the large parentheses in (5c). Therefore, since $-\left[\varphi / E U^{\prime}(\pi)\right] p^{* \prime}\left(q_{I}^{*}\right) x_{I}^{*} \geqslant 0$ and $R^{\prime}\left(q_{I}\right) \leqslant R^{\prime}\left(q_{r}\right), q_{I}^{*}>q_{r}^{*}$ follows from (5c) and (10c). When $x_{I}^{*} \leqslant x_{r}^{*}, q_{I} \geqslant q_{r}$ and $q_{I}^{*}>q_{r}^{*}$, the sales-output equality implies $x_{I}>x_{r}$, which contradicts the initial supposition. Hence $x_{I}>x_{r}, q_{I}<q_{r}$, and $x_{I}-q_{I}>x_{r}-q_{r}$.

\section{Proof of Proposition 3}

(i) Let $\rho \equiv \bar{\rho}+\varepsilon$ with $\varepsilon \geqslant 0$. Then $\varphi=0$ from the definition of $\bar{\rho}$. Hence $R^{\prime}\left(q_{I}\right)=C^{*^{\prime}}\left(x_{I}\right)$ from (10b). Also, from (10d), (10c) can be rewritten as $R^{\prime}\left(q_{I}\right)=(1-\rho) R^{*^{\prime}}\left(q^{*}\right)$. The first-order conditions for $x_{I}, x_{I}^{*}$ and $q$ ( (and hence also $q_{I}$ ) are now independent of the utility function, the covariance term and the features of the distribution of $\lambda$.

(ii) Let $\rho \equiv \bar{\rho}+\varepsilon$ with $\varepsilon<0$. Then, $\varphi>0$ from the definition of $\bar{\rho}$. Substituting the righthand side of (10e) for $\varphi$ in expressions (10b) and (10c) yields, respectively,

$$
\begin{aligned}
& R^{\prime}\left(q_{I}\right)=C^{*^{\prime}}\left(x_{I}\right)+\left(\alpha \frac{E U^{\prime}\left(\pi_{\lambda}\right) E \lambda+\operatorname{cov}\left(U^{\prime}\left(\pi_{\lambda}\right), \lambda\right)}{E U^{\prime}(\pi)}-\rho\right) p^{*}\left(q_{I}^{*}\right) \\
& R^{\prime}\left(q_{I}\right)=(1-\rho) R^{*^{\prime}}\left(q_{I}^{*}\right)-\left(\alpha \frac{E U^{\prime}\left(\pi_{\lambda}\right) E \lambda+\operatorname{cov}\left(U^{\prime}\left(\pi_{\lambda}\right), \lambda\right)}{E U^{\prime}(\pi)}-\rho\right) p^{*^{\prime}}\left(q_{I}^{*}\right) x_{I}^{*}
\end{aligned}
$$

These expressions clearly depend on the utility function, the covariance term and the distribution features of $\lambda$.

\section{Proof of Corollary}

From (10e), $\varphi>0$ at $\rho=\alpha E \lambda$.

(i) Suppose $x_{I} \leqslant x_{c}$ at $\rho=\alpha E \lambda$. This implies $R^{\prime}\left(q_{I}\right)=C^{\prime}\left(x_{I}\right) \leqslant C^{\prime}\left(x_{c}\right)=R^{\prime}\left(q_{c}\right)$ (from (10a) and (7a)) and hence $q_{I} \geqslant q_{c}$. Also, because $C^{*^{\prime}}\left(x_{I}^{*}\right)+\left(\varphi / E U^{\prime}(\pi)\right) p^{*}\left(q_{I}^{*}\right)$

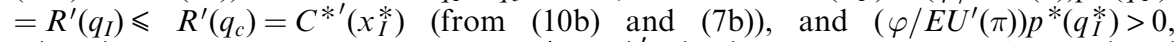
$x_{I}^{*}<x_{c}^{*}$. Furthermore, because $\left(\varphi / E U^{\prime}(\pi)\right) p^{* \prime}\left(q_{I}^{*}\right) x_{I}^{*}<0$ and $R^{\prime}\left(q_{I}\right) \leqslant R^{\prime}\left(q_{c}\right), q_{I}^{*}>q_{c}^{*}$ follows at $\rho=\alpha E \lambda$ from (10c) and (7c). With $q_{I} \geqslant q_{c}, x_{I}^{*}<x_{c}^{*}$ and $q_{I}^{*}>q_{c}^{*}$, the salesproduction equality implies $x_{I}>x_{c}$, which contradicts the initial supposition. Hence $x_{I}>x_{c}$ and $q_{I}<q_{c}$.

(ii) Suppose $x_{I}^{*} \geqslant x_{c}^{*}$, implying $C^{* \prime}\left(x_{I}^{*}\right) \geqslant C^{* \prime}\left(x_{c}^{*}\right)$. From combining (10b) and (10c), $C^{*^{\prime}}\left(x_{I}^{*}\right)=(1-\rho) R^{*^{\prime}}\left(q_{I}^{*}\right)-\left(\varphi / E U^{\prime}(\pi)\right)\left(p^{*}\left(q_{T}^{*}\right)+p^{* \prime}\left(q^{*}\right) x_{I}^{*}\right)$ follows, while $(7 \mathrm{~b})$ and (7c) imply $C^{*^{\prime}}\left(x_{c}^{*}\right)=(1-\alpha E \lambda) R^{*^{\prime}}\left(q_{c}^{*}\right)$. With $p^{*}\left(q_{I}^{*}\right)+p^{*^{\prime}}\left(q_{I}^{*}\right) x_{I}^{*}>0$ (since $R^{*^{*}}\left(q_{I}^{*}\right)>0$ 
and $\left.q_{I}^{*}>x_{I}^{*}\right)$ and at $\rho=\alpha E \lambda, C^{* \prime}\left(x_{I}^{*}\right) \geqslant C^{* \prime}\left(x_{c}^{*}\right)$ implies $R^{* \prime}\left(q_{I}^{*}\right)>R^{* \prime}\left(q_{c}^{*}\right)$, hence $q_{I}^{*}<q_{c}^{*}$. Together with $x_{I}>x_{c}$ and $q_{I}<q_{c}$ (see (i)), the sales-production equality then implies $x_{I}^{*}<x_{c}^{*}$, which contradicts the initial supposition. Hence $x_{I}^{*}<x_{c}^{*}$.

(iii) Since $x_{I}>x_{c}$ and $q_{I}<q_{c}$ (see (i)), $x_{I}-q_{I}>x_{c}-q_{c}$.

\section{Proof of Proposition 4}

It proves convenient to substitute $R^{*}\left(q_{I}^{*}\right)-p^{*}\left(q_{I}^{*}\right) x_{I}^{*}$ for $I$ in (9), thus translating the constrained optimization problem into an unconstrained one, given by

$$
\max _{x_{I}, x x_{T}^{*}, q_{T}^{*}} E \hat{U}=(1-\alpha) U\left(\pi_{0}\right)+\alpha \int_{\lambda} U\left(\pi_{\lambda}\right) f_{\lambda} \mathrm{d} \lambda,
$$

where $E \hat{U}$ denotes expected utility $E U$ evaluated at $I=R^{*}\left(q_{\hat{I}}^{*}\right)-p^{*}\left(q_{\hat{I}}^{*}\right) x_{I}^{*}$. Let partial derivatives of $E \hat{U}$ be denoted by subscripts. The first-order conditions obtained $\left(E \hat{U}_{x_{I}}=0, E \hat{U}_{x_{I}^{*}}=0\right.$ and $\left.E \hat{U}_{q_{I}^{*}}=0\right)$ are totally differentiated with respect to $\rho$. Then, with $E \hat{U}_{x_{I} \rho}=0$ and $E \hat{U}_{x_{I} x_{I}^{*}}=-E \hat{U}_{x_{I} q \hat{I}^{*}}=E U^{\prime}(\pi) R^{\prime \prime}\left(q_{I}\right)<0, \mathrm{~d} x_{I} / \mathrm{d} \rho$ is equal to

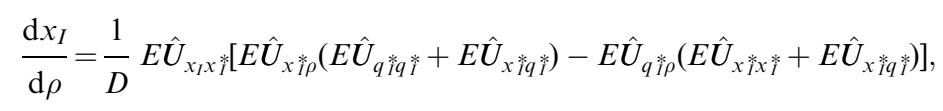

with

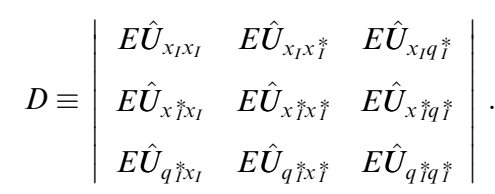

Standard sufficient conditions that guarantee the second-order conditions associated with the maximization problem are that the diagonal terms of $D$ are negative and dominate the sum of the absolute values of the off-diagonal terms in the same row (column). From the second-order conditions, $D<0$. In (A1), $E \hat{U}_{x * \rho} \equiv \partial E \hat{U}_{x *} / \partial \rho$ and $E \hat{U}_{q * \hat{I} \rho} \equiv \partial E \hat{U}_{q *} / \partial \rho$ are given by

(A2a) $E \hat{U}_{x \stackrel{*}{\rho} \rho}=\left[-\left(R^{*}\left(q_{I}^{*}\right)-p^{*}\left(q_{I}^{*}\right) x_{I}^{*}\right) B+E \hat{U}^{\prime}(\pi)\right] p^{*}\left(q_{I}^{*}\right)$

$$
E \hat{U}_{q \dddot{I} \rho}=-\left(R^{*}\left(q_{I}^{*}\right)-p^{*}\left(q_{I}^{*}\right) x_{I}^{*}\right) B p^{* \prime}\left(q_{I}^{*}\right) x_{I}^{*}-E \hat{U}^{\prime}(\pi)\left(R^{* \prime}\left(q_{I}^{*}\right)-p^{* \prime}\left(q_{I}^{*}\right) x_{I}^{*}\right)
$$

with

$$
B \equiv(1-\alpha) U^{\prime \prime}\left(\pi_{0}\right) z+\alpha \int_{\lambda} U^{\prime \prime}\left(\pi_{\lambda}\right)(z-\lambda) f_{\lambda} \mathrm{d} \lambda
$$

and

$$
z \equiv \alpha \frac{E U^{\prime}\left(\pi_{\lambda}\right) E \lambda+\operatorname{cov}\left(U^{\prime}\left(\pi_{\lambda}\right), \lambda\right)}{E U^{\prime}(\pi)}, \quad \rho<z<1
$$

In (A1), $E \hat{U}_{x_{I} x_{I}^{*}<0,}<\hat{U}_{q_{I}^{*} q_{I}^{*}}+E \hat{U}_{x_{I}^{*} q_{I}^{*}<0}$ and $E \hat{U}_{x_{I}^{*} x_{I}^{*}}+E \hat{U}_{x_{I}^{*} q_{I}^{*}<0}$ (from the sufficient conditions for the second-order conditions). From (A1), the sign of $\mathrm{d} x_{I} / \mathrm{d} \rho$ also depends on the signs of $E \hat{U}_{x * \rho}$ and $E \hat{U}_{q * \rho}^{*}$. If $E \hat{U}_{x * \rho}>0$ and $E \hat{U}_{q * \rho}<0$, then $\mathrm{d} x_{I} / \mathrm{d} \rho<0$. For a risk-neutral MNE, $U^{\prime \prime}(\cdot)=0$ and hence $B=0$ from (A3). With $B=0$, the remaining terms in $(\mathrm{A} 2 \mathrm{a})$ and $(\mathrm{A} 2 \mathrm{~b})$ represent the direct export subsidy effect, implying $E \hat{U}_{x \stackrel{*}{\rho} \rho}>0$ and $E \hat{U}_{q_{I}^{*} \rho}<0$ (since $R^{* \prime}\left(q_{I}^{*}\right)-p^{* \prime}\left(q_{I}^{*}\right) x_{I}^{*}>0$, representing the marginal revenue of exports). Hence, risk neutrality always implies that $\mathrm{d} x_{I} / \mathrm{d} \rho<0$.

Under risk aversion, however, $B$ is typically non-zero. In (A2a) and (A2b) the terms in $B$ measure the combined effect of a premium reduction through risk aversion and prudence on the demand for insurance. If $B \leqslant 0$, then this effect reinforces the export 
subsidy effect (implying $E \hat{U}_{x * \rho \rho}>0$ and $\left.E \hat{U}_{q \tilde{I} \rho}<0\right)$ since $R^{*}\left(q_{I}^{*}\right)-p^{*}\left(q_{I}^{*}\right) x_{I}^{*}=I>0$. Using (A3) and (A4), and with $E U^{\prime \prime}\left(\pi_{\lambda}\right) / E U^{\prime}\left(\pi_{\lambda}\right)=E U^{\prime \prime}(\pi) / E U^{\prime}(\pi)=U^{\prime \prime} / U^{\prime}$ under CARA, the following expression for $B$ is obtained:

$$
B=-\alpha\left[-\left(U^{\prime \prime} / U^{\prime}\right) \operatorname{cov}\left(U^{\prime}\left(\pi_{\lambda}\right), \lambda\right)+\operatorname{cov}\left(U^{\prime \prime}\left(\pi_{\lambda}\right), \lambda\right)\right]
$$

A sufficient condition for $B \leqslant 0$, and hence for $\mathrm{d} x_{I} / \mathrm{d} \rho<0$, is therefore

$$
-\left(U^{\prime \prime} / U^{\prime}\right) \operatorname{cov}\left(U^{\prime}\left(\pi_{\lambda}\right), \lambda\right) \geqslant-\operatorname{cov}\left(U^{\prime \prime}\left(\pi_{\lambda}\right), \lambda\right) \text {. }
$$

Under CARA, $\operatorname{cov}\left(U^{\prime}\left(\pi_{\lambda}\right), \lambda\right)=-\operatorname{cov}\left(U^{\prime \prime}\left(\pi_{\lambda}\right), \lambda\right)>0$, hence condition (A6) reduces to $-\left(U^{\prime \prime} / U^{\prime}\right) \geqslant 1$. Furthermore, after calculating $\mathrm{d} x_{I} / \mathrm{d} \rho$, total differentiation of the firstorder conditions $E \hat{U}_{x_{I}^{*}}=0$ and $E \hat{U}_{q_{I}^{*}}=0$ yields the following expression for $\mathrm{d} x_{I}^{*} / \mathrm{d} \rho$ :

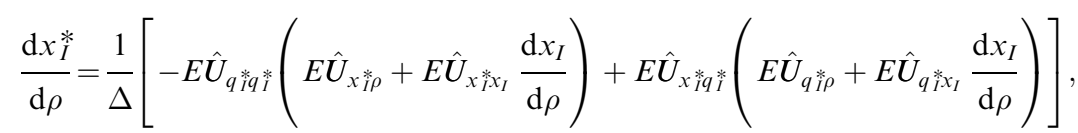

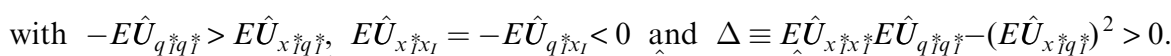
Thus, if $B \leqslant 0$, then $\mathrm{d} x_{I} / \mathrm{d} \rho<0$ (from A1) and $E \hat{U}_{x \breve{I} \rho}>-E \hat{U}_{q * \rho}$ (from (A2a) and (A2b)). Hence, $\mathrm{d} x x_{I}^{*} / \mathrm{d} \rho>0$ from (A7).

\section{ACKNOWLEDGMENTS}

I am indebted to Leon Bettendorf, Dermot Leahy and Heinrich Ursprung for constructive comments. In addition, I thank Filip Abraham, Richard Baldwin, Joseph Francois and ERWIT conference participants in Helsinki (September 1997) for helpful comments on an early version of the paper, and seminar participants of the Economics Department at the University of Glasgow and two anonymous referees for helpful suggestions. The research work reported in this paper was financially assisted and supported through a research fellowship awarded by the ASEAN-EC Management Centre.

\section{NOTES}

1. Among others, see Das (1983) and Itagaki $(1989,1991)$

2. Papers in this area concentrate on exchange rate and price uncertainty and include Batra and Hadar (1979), Holthausen (1979), Feder et al. (1980), Katz et al. (1982), Kawai and Zilcha (1986), and Broll and Zilcha (1992). See Caves (1996) for a complete survey.)

3. During the period 1988-93, export credits increased by 250\% (Kuhn et al. 1995).

4. While economies in transition were the main beneficiaries in the late 1980s, export credits to South-East Asian countries rose dramatically in the 1990s (COFACE 1998, p. 254).

5. Stephens (1999), p. 27.

6. Krugman (1999, p. 68) claims that the financial crisis in South-East Asia entailing massive defaults in the late 1990s was caused by severe moral hazard problems in the credit system.

7. The setup is akin to Calderon-Rossell (1985), Itagaki (1989) and Broll and Zilcha (1992).

8. I focus on interior solutions as the availability of export credit insurance is unlikely to determine the actual location decision of the firm.

9. The assumption of both plants producing an identical good is not crucial. It merely implies that there will be only one-way trade in the model, while differentiated products are likely to create two-way trade between subsidiaries.

10. Firm-specific factors are typically assumed in similar MNE models (e.g. see Itagaki 1989).

11. It is assumed that the firm cannot influence $\alpha$. The implications of making $\alpha$ dependent on the MNE's actions are briefly addressed in the final section.

12. With concave revenue functions and increasing marginal costs, second-order conditions are satisfied (see Broll and Zilcha 1992).

13. This result has been established in the literature for other but similar forms of revenue uncertainty (see, for instance, Broll and Zilcha 1992). The proof follows directly from $(5 a-5 c)$ and $(7 \mathrm{a}-7 \mathrm{c})$.

14. Export insurance generally requires that the products covered originated in the exporting country (Shapiro 1998, p. 307). Although MNEs can buy foreign investment insurance, that

(C) The London School of Economics and Political Science 2002 
policy only provides coverage against certain political risks (e.g. confiscation, expropriation or nationalization by the host government), and not against foreign commercial risks. By contrast, export credit insurance includes coverage against political and commercial risk of default alike (Stephens 1999, p. 91).

15. This constraint also captures the fact that over-insurance of export contracts is legally prohibited.

16. Evidently, the premium is assumed not to be prohibitive, meaning that the MNE will always take some insurance $(I>0)$.

17. As in Itagaki (1991), second-order conditions are assumed to be satisfied. A detailed discussion of these second-order conditions can be obtained from the author upon request.

18. The MNE's international production allocation with exchange rate (price) uncertainty and forward (futures) markets are extensively discussed in the literature (see, e.g. Broll and Zilcha 1992).

19. A separation theorem has been established in different setups of decision-making under uncertainty (e.g. see Holthausen 1979; Feder et al. 1980; Katz et al. 1982).

20. The coverage depends, of course, on the firm's attitude to risk and the default rate's distribution.

21. This follows from (10d), which holds only for $\rho>\alpha E \lambda$. At $\rho$, (10e) holds instead of (10d).

22. By contrast, a change in the risk premium in financial markets affects production in both MNE plants in the same direction.

23. Note that for a risk-neutral firm, which also purchases insurance at a subsidized rate, this is the only effect of a premium reduction.

24. If $A>B$, CARA implies $-U^{\prime \prime}(A) / U^{\prime}(A)=-U^{\prime \prime}(B) / U^{\prime}(B)$. Since $U^{\prime \prime}<0, U^{\prime}(A)<U^{\prime}(B)$. CARA therefore requires $-U^{\prime \prime}(A)<-U^{\prime \prime}(B)$, which implies $U^{\prime \prime \prime}>0$. Similarly, $U^{\prime \prime \prime}>0$ under decreasing absolute risk aversion (DARA). For utility functions where $U^{\prime \prime}$ is a constant, $U^{\prime \prime \prime}=0$ and hence $\mathrm{d} x_{I} / \mathrm{d} \rho<0$ and $\mathrm{d} x_{I}^{*} / \mathrm{d} \rho>0$ always occur, just like under risk neutrality. However, such utility functions imply increasing absolute risk aversion (IARA), which is typically considered to be an undesirable property (see e.g. Huang and Litzenberger 1988).

25. The concept of 'prudence' (so labelled by Kimball 1990) is measured by $-U^{\prime \prime \prime} / U^{\prime \prime}$. While risk aversion is crucial to determine the optimal value of variables, prudence is important to determine the optimal response of those variables to a change in an exogenous parameter.

26. For firms with DARA, the increase in profits caused by a premium reduction will in addition diminish the firm's risk aversion, which lessens its need for insurance and further weakens the firm's incentive to contract its foreign production.

27. It is worth mentioning that a MNE's optimal response to a premium rate reduction is different if export insurance is taxed and the coverage constraint is not binding $(\rho \geqslant \bar{\rho}>\alpha E \lambda)$. Since the separation property applies in that case, a change in the firm's attitude towards risk induced by the premium reduction does not affect the production decision. Then, MNEs expand production in both their home and their host plant, which follows immediately from (10a)(10d) with $\varphi=0$.

28. This was first pointed out by Shavell (1979).

\section{REFERENCES}

Abraham, F., Couwenberg, I. and Dewit, G. (1992). Towards an EC policy on export financing subsidies: lessons from the 1980s and prospects for future reform. The World Economy, 15, 389-405.

BATRA, R. N. and HADAR, J. (1979). Theory of the multinational firm: fixed versus floating exchange rates. Oxford Economic Papers, 31, 258-69.

BROLL, U. and ZILCHA, I. (1992). Exchange rate uncertainty, futures markets and the multinational firm. European Economic Review, 36, 815-26.

CAlderon-Rossell, J. R. (1985). Towards the theory of foreign direct investment. Oxford Economic Papers, 37, 282-91.

CAves, R. E. (1996). Multinational Enterprise and Economic Analysis, 2nd edn. Cambridge: Cambridge University Press.

COFACE (1998). Risque Pays. Paris: COFACE.

DAS, S. P. (1983). Multinational enterprise under uncertainty. Canadian Journal of Economics, 16, $420-28$.

FEDER, G., JUST, R. and SChmitz, A. (1980). Futures markets and the theory of the firm under price uncertainty. Quarterly Journal of Economics, 94, 317-28.

Finger, M. and Schuknecht, L. (1999). Trade, Finance and Financial Crisis. Geneva: World Trade Organization.

(C) The London School of Economics and Political Science 2002 
Holthausen, D. M. (1979). Hedging and the competitive firm under price uncertainty. American Economic Review, 69, 989-95.

HuAng, C-F. and Litzenberger, R. H. (1988). Foundations for Financial Economics. New York: North-Holland.

ITAGAKI, T. (1989). The multinational enterprise under the threats of restriction on profit repatriation and exchange control. Journal of Development Economics, 31, 369-77.

(1991). A two-step decision model of the multinational enterprise under foreign demand uncertainty. Journal of International Economics, 30, 185-90.

Katz, E., PAroush, J. and KahanA, N. (1982). Price uncertainty and the price discriminating firm in international trade. International Economic Review, 23, 389-400.

KAWAI, M. and ZILCHA, I. (1986). International trade with forward-futures markets under exchange rate and price uncertainty. Journal of International Economics, 20, 83-98.

Kimball, M. (1990). Precautionary saving in the small and in the large. Econometrica, 58, 53-73.

Krugman, P. (1999). The Return of Depression Economics. London: Penguin Press.

Kuhn, M., Horvath, B. and Jarvis, C. (1995). Officially Supported Export Credits. Recent Developments and Prospects, World Economic and Financial Surveys. Washington: International Monetary Fund, March.

Shapiro, A. C. (1998). Foundations of Multinational Financial Management, 3rd edn. Englewood Cliffs, NJ: Prentice-Hall.

SHAVELl, S. (1979). On moral hazard and insurance. Quarterly Journal of Economics, 93, 541-62.

Stephens, M. (1999). The Changing Role of Export Credit Agencies. Washington: International Monetary Fund. 